\title{
Article \\ Isolation and Characterization of Pediococcus sp. HLV1 from Fermented Idly Batter
}

\author{
Harika Katepogu ${ }^{1}$, Young-Jung Wee ${ }^{2}\left(\mathbb{D}\right.$, Khalid S. Almaary ${ }^{3}$, Yahya B. Elbadawi ${ }^{3}$, Ramachawolran Gobinath ${ }^{4}{ }^{\mathbb{D}}$, \\ Suresh V. Chinni ${ }^{5, * \mathbb{D}}$ and Veeranjaneya Reddy Lebaka $1, * \mathbb{C}$
}

check for updates

Citation: Katepogu, H.; Wee, Y.-J.; Almaary, K.S.; Elbadawi, Y.B.; Gobinath, R.; Chinni, S.V.; Lebaka, V.R. Isolation and Characterization of Pediococcus sp. HLV1 from Fermented Idly Batter. Fermentation 2022, 8, 61 . https://doi.org/10.3390/ fermentation 8020061

Academic Editors: Chih Yao Hou, Bao-Hong Lee and Ming-Kuei Shih

Received: 31 December 2021

Accepted: 26 January 2022

Published: 30 January 2022

Publisher's Note: MDPI stays neutral with regard to jurisdictional claims in published maps and institutional affiliations.

Copyright: (C) 2022 by the authors. Licensee MDPI, Basel, Switzerland. This article is an open access article distributed under the terms and conditions of the Creative Commons Attribution (CC BY) license (https:// creativecommons.org/licenses/by/ $4.0 /)$.
1 Department of Microbiology, Yogi Vemana University, Kadapa 516005, India; harika.katepogu@gmail.com

2 Department of Food Science and Technology, Yeungnam University, Gyeongsan 712-719, Korea; yjwee@ynu.ac.kr

3 Department of Botany and Microbiology, College of Science, King Saud University, P.O. Box 2455, Riyadh 11451, Saudi Arabia; maarykhalid@gmail.com (K.S.A.); yahiabadawy78@gmail.com (Y.B.E.)

4 Department of Foundation, RCSI \& UCD Malaysia Campus, No 4, Jalan Sepoy Lines, Georgetown 10450, Malaysia; r.gobinath@rcsiucd.edu.my

5 Department of Biotechnology, Faculty of Applied Sciences, AIMST University, Bedong 08100, Malaysia

* Correspondence: v_suresh@aimst.edu.my (S.V.C.); lvereddy@yahoo.com (V.R.L.)

\begin{abstract}
The aim of the present study is the isolation and characterization of the lactic acid bacteria from idly batter, a traditional Indian fermented product. To achieve the aim, 10 idly batter samples were selected from different regions of Kadapa district. In the primary isolation and screening process, 50 lactic-acid-producing bacteria were isolated, and from them, six strains were selected based on their lactic acid yielding capacity for further evaluation. The selected cultures were studied for their phenotypic characters, and all cultures were Gram positive, cocci, and catalase negative. All the six strains were tested for their growth and lactic acid production at above $35^{\circ} \mathrm{C}$, and finally, one strain that showed good growth at $50{ }^{\circ} \mathrm{C}$ was selected for further characterization. Molecular characterization by $16 \mathrm{~S}$ rRNA gene analysis and BLAST analysis revealed $99 \%$ similarity with Pediococcus pentosaceus Ni1142. The isolated culture was named as Pediococcus sp. HLV1, and the sequence was submitted to the NCBI databank as accession number MH921241. The isolated strain is able to utilize a wide range of carbohydrate substrates including glucose, fructose, sucrose, lactose, maltose, and xylose. The major fermentation product from glucose is lactic acid. Pediococcus sp. HLV1 showed optimum growth and production of lactic acid with glucose as carbon source $(10 \%)$ and yeast extract as nitrogen source $(0.3 \%)$ at $\mathrm{pH} 7.0$ and $40{ }^{\circ} \mathrm{C}$. As well-known probiotic bacteria, the isolated Pediococcus spp. also showed antimicrobial activity against both Gram-positive and Gram-negative bacteria and more specifically inhibited Gram-positive Bacillus. Using the above optimal conditions, lactic acid from a fresh mango peel extract was studied, and at the end of the fermentation, 5.2\% $(v / v)$ of lactic acid was produced. In conclusion, the isolated LAB Pediococcus sp. strain HLV1 is able to grow and produce lactic acid at a high temperature $\left(45^{\circ} \mathrm{C}\right)$ and to survive at $50{ }^{\circ} \mathrm{C}$. Mango peel, a by-product of mango pulp industries, can be utilized as one of the economically cheap feedstocks for industrial production of lactic acid by the Pediococcus sp. strain HLV1.
\end{abstract}

Keywords: isolation; characterization; Pediococcus pentosaceus; idly batter; optimization; mango peel fermentation

\section{Introduction}

Lactic acid (2-hydroxypropanoic acid, $\mathrm{CH}_{3}-\mathrm{CH}(\mathrm{OH})-\mathrm{COOH}$ ) is a versatile natural organic acid having no color and can be clearly dissolved in water and alcohol. It has wide applications in the food, agriculture, medical, and pharmaceutical industries. Lactic acid (LA) is one of the very important and valuable metabolites produced through fermentation and selected as one of the most promising value-added microbial products. Its world market is estimated to cross USD 8.77 billion by 2025 with $18.7 \%$ annual growth [1]. 
In LA production, microorganisms play an important role, and they are present in soil and natural and fermented food products. Selection of an appropriate lactic acid bacterial $(\mathrm{LAB})$ strain is very important to produce pure and enantioselective $\mathrm{L}(+) / \mathrm{D}(-)$ lactic acid. Microorganisms are able to produce pure $\mathrm{L}(+)$ or $\mathrm{D}(-)$ lactic acid. To reduce the production cost through fermentation, microbes must have the ability to rapidly ferment low-cost crude materials, to require a limited quantity of nutrients, and to produce high yields of lactic acid under conditions of low $\mathrm{pH}$ and high temperature for the production of a low number of by-products [2,3]. There are a lot of organisms from bacteria, yeast, and fungi for lactic acid fermentation. Most of the industrial lactic acid is produced by using lactic acid bacteria [4,5]. Lactic acid bacteria have been isolated from a variety of sources. In most fermented foods, especially foods of/in India, the fermentation relates to cereals and legumes by lactic acid bacteria (LAB). Idly batter contains dehulled black gram and milled/powdered rice, and the preparation method is different in different regions of South India mainly in the ratio of rice and black gram or in the time of soaking of the components and the fermentation period of the final batter [6]. In the leavening process of batter and acid production, heterofermentative Leuconostoc mesenteroides and homofermentative Streptococcus faecalis and probiotic Lactobacillus plantarum, Lactobacillus lactis, and Pediococcus pentosaceus are major lactobacillus candidate organisms that are present in idly batter [7].

As LA has a high demand in chemical and biomedical manufacturing sectors, it is very essential to search for economically cheap feedstock for its production [8]. Various studies were carried out on lactic production from different agroindustrial residues, such as sugarcane bagasse, date juice, and coffee mucilage [9-11]. India is the largest producer of mango with 22 million tons per annum production, and most amount is consumed fresh, another amount is used in the preparation of mango pulp/puree, and rest is used to export to many countries in the world. In the pulp preparation process, mango peel and kernels are generated as by-products. During processing, $25 \%$ to $40 \%$ is generated as waste byproduct, and usually, it is dumped in open areas by factories, causing environmental pollution. Mango peel is one of the rich sources of fermentable sugars, and it has proved to be one of the economically cheap and feasible feedstocks for ethanol and butanol production [12,13]. Reports on the utilization of mango peel for LA are very scarce [14,15]. Hence, the present study aims for the isolation and characterization of LAB from idly batter.

\section{Materials and Methods}

\subsection{Isolation of Lactic Acid Bacteria}

For the isolation of LAB, $1 \mathrm{gm}$ of idly batter was taken and serially diluted using sterile distilled water. These diluted samples were plated using the spread plate technique on deMan Rogosa Sharpe (MRS) agar plates and incubated at $37^{\circ} \mathrm{C}$ for $24 \mathrm{~h}$. White and clear elevated colonies were selected, and the $\mathrm{CaCO}_{3}$ method with bromocresol purple was used to select acid-producing bacteria. Isolates that produce acids form a clear zone around them, which were further purified through repeated streaking on MRS agar plates. The purified and acid-producing stains were maintained on MRS agar medium at $4{ }^{\circ} \mathrm{C}$ for short-term storage, and the resuspended culture vials in $20 \%(v / v)$ glycerol at $-80{ }^{\circ} \mathrm{C}$ for long-term storage.

\subsection{Morphological and Physiological Characterization}

The colonies were identified based on Gram staining, size, shape, and motility of the organism by using a microscope (Leica, Mumbai, India). The physiological characteristics were determined according to different biochemical tests, such as catalase, hydrogen sulfide $\left(\mathrm{H}_{2} \mathrm{~S}\right)$, indole, urease, methyl red, and Voges-Proskauer. For sugar assimilation tests, specific sugars, such as glucose, sucrose, lactose, mannose, fructose, and maltose, were added to the carbohydrate media, and the acid production was identified by color change. Based on phenotypic and biochemical characteristics, preliminary identification was performed using Bergey's manual of determinative bacteriology. 
Scanning Electron Microscope (SEM)

For SEM analysis, $1 \mathrm{~mL}$ of well-grown $(24 \mathrm{~h})$ isolated culture was taken, and the cells were separated by centrifuge at $10,000 \times g \mathrm{rpm}$ for $10 \mathrm{~min}$. Then the obtained cell pellet was washed twice with phosphate-buffered solution (PBS). To the clear pellet, $1 \mathrm{~mL}$ of glutaraldehyde (2-3\%) was added. It was incubated at $4{ }^{\circ} \mathrm{C}$ for $4 \mathrm{~h}$ and pelleted the cells at $10,000 \mathrm{rpm}$. The pellet was further washed with $10-100 \%$ alcohol in a graded manner, and the dehydrated cells were sputter-coated with gold at $25 \mathrm{~mA}$ for $250 \mathrm{~s}$ and observed by a scanning electron microscope (JSM-6460 LV; JEOL, Tokyo, Japan) at $5.0 \mathrm{kV}$ and at $20 \mathrm{KX}$ magnification [16].

\subsection{Molecular Identification}

By using morphological and physiological characteristics, preliminary identification was performed on the isolates. For the molecular identification and characterization, fresh cultures were prepared, and DNA was isolated from fully grown culture. For the bacterial 16S rRNA gene, amplification reaction was carried out using PCR with Taq DNA polymerase, 27 forward primer ( $5^{\prime}$ AGA GTT TGA TCC TGG CTC AG $3^{\prime}$ ), and 1492 reverse primer $\left(3^{\prime}\right.$ GGT TAC CTT GTT ACG ACT T $\left.5^{\prime}\right)$. Initial denaturation was carried out at $95^{\circ} \mathrm{C}$ for $10 \mathrm{~min}$, and then 30 cycles of amplification were followed by secondary denaturation at $95^{\circ} \mathrm{C}$ for $2 \mathrm{~min}$. Primer annealing was performed at $58^{\circ} \mathrm{C}$ for $1 \mathrm{~min}$, which was then allowed for primer extension at $72{ }^{\circ} \mathrm{C}$ for $2 \mathrm{~min}$. Amplified DNA was checked by using $1 \%$ agarose gel, and concentration was quantified by using a spectrophotometer. The amplified PCR product was purified with a Qiagen kit (Qiagen Ltd., Crawley, UK). BLAST and the multiple alignment program Clustal $\mathrm{W}$ were used for the data sequence analysis. MEGA7 software was used for the construction of a phylogenetic tree and knowing the percentage of similarity between related microorganisms [16].

\subsection{Optimization of Fermentation Factors}

MRS medium was used for preliminary optimization studies of LA fermentation. The parameters tested were carbon sources (glucose, lactose, fructose, sucrose, xylose, and soy flour), nitrogen sources (peptone, yeast extract, beef extract, yeast extract + beef extract, yeast extract + peptone, and beef extract + peptone), $\mathrm{pH}(5.0,6.0,7.0,8.0$, and 9.0), and temperature $\left(20,25,30,35,40,45\right.$, and $\left.50^{\circ} \mathrm{C}\right)$, respectively, to create the optimized conditions for good yield of LA by one factor using one-time method. Growth, change in $\mathrm{pH}$, and the lactic acid yield were evaluated during all the experiments.

\subsection{Antimicrobial Activity}

To evaluate the antimicrobial potential of the isolated culture, a cell-free supernatant was prepared by centrifuging the culture broth at $10,000 \times g$ rpm for $5 \mathrm{~min}$. Different doses $(10,20,50$, and $100 \mu \mathrm{L})$ of the cell-free supernatant were tested for antimicrobial activity against both Gram-negative (E. coli) and Gram-positive (B. subtilis) bacteria through the well-plate method. Bacterial culture suspension grown overnight was evenly spread on preprepared agar Petri plates. Then wells were prepared using a $6 \mathrm{~mm}$ agar medium borer and placed above the prepared cell-free suspension of the selected culture. The plates were incubated for $16 \mathrm{~h}$ at $37^{\circ} \mathrm{C}$ and measured the inhibition zone diameter in millimeters using a Vernier caliper [17].

\subsection{Lactic Acid Production from Mango Peel}

Mango peel was collected from Varsha Fruit Pulp Industries Ltd., Koduru, Kadapa, India. It was macerated using a mixer (Panasonic mixer, Model: 340 ) and treated with 1\% $(v / v)$ pectinase, Trizyme 50 (Triton Chemicals, Mysore, India). Liquid containing sugars was extracted with the help of a cheesecloth by squeezing after the enzymatic digestion. The extract was subjected to analysis of reducing sugar and juice yield. The $\mathrm{pH}$ of the extract used as a culture medium for lactic acid production was adjusted to 7.0, and it was 
supplemented with peptone $(0.3 \%)$ to assess the effect of the nutrients on the fermentation process using an unsupplemented medium as the control [12].

\subsection{Analysis}

Reducing sugars present in fresh mango peel and pectinase extract were quantified by DNS (3,5-dinitrosalicylic acid) method [18]. The cell concentration was measured by using a UV-VIS spectrophotometer (1800; Shimadzu, Kyoto, Japan) at $600 \mathrm{~nm}$. The cell count was calculated using an Improved Neubauer counting chamber for bacteria. $\mathrm{pH}$ change was tested by using a $\mathrm{pH}$ meter. High-performance liquid chromatography (HPLC) was used for the estimation of the amount of LA present in fermented samples. For estimation, samples were collected at 24, 48, and $72 \mathrm{~h}$ after inoculation and diluted to 1:10 with distilled water. The diluted samples were centrifuged and filtered through a $0.45 \times g \mu \mathrm{m}$ PTFE membrane. The analysis was performed with a reverse-phase $C 18$ column using an injection volume of $20 \mu \mathrm{L}$ and detection at $210 \mathrm{~nm}$ using the chromatographic system (LC10A; Shimadzu, Japan) coupled with a UV detector. The mobile phase employed was $0.008 \mathrm{M}$ sulfuric acid at a flow rate of $1 \mathrm{~mL} / \mathrm{min}$ in an isocratic mode of elution. Each sample was injected two times, and quantification was performed using sodium lactate standards (Sigma-Aldrich, St. Louis, MO, USA).

\subsection{Statistical Analysis}

All experiments and analyses were conducted in triplicate. The results were expressed as mean $\pm \mathrm{SD}$ (standard deviation). All statistical analyses were carried out using statistical differences among different factors, which were determined using ANOVA.

\section{Results and Discussion}

Lactic acid bacteria were isolated from the overnight fermented idly batter samples. A total of 50 isolates of lactic acid bacteria were selected through preliminary screening. From those, 6 isolates that have more clear zones with bromocresol purple and $\mathrm{CaCO}_{3}$ were selected for further screening and characterization. All 6 isolated cultures were Grampositive, cocci, arranged in tetrads and pairs, and catalase-negative. Table 1 and Figure 1 show the results of the morphological and physiological characteristics of the isolated strains. Most of the previous investigators used fermented batters, fruits, vegetables, and milk products for the isolation of lactic-acid-producing microorganisms [19-21]. Mostly lactic acid bacteria are nonmotile, cocci, or rod in shape and homo- or heterofermentative and catalase-negative [22].
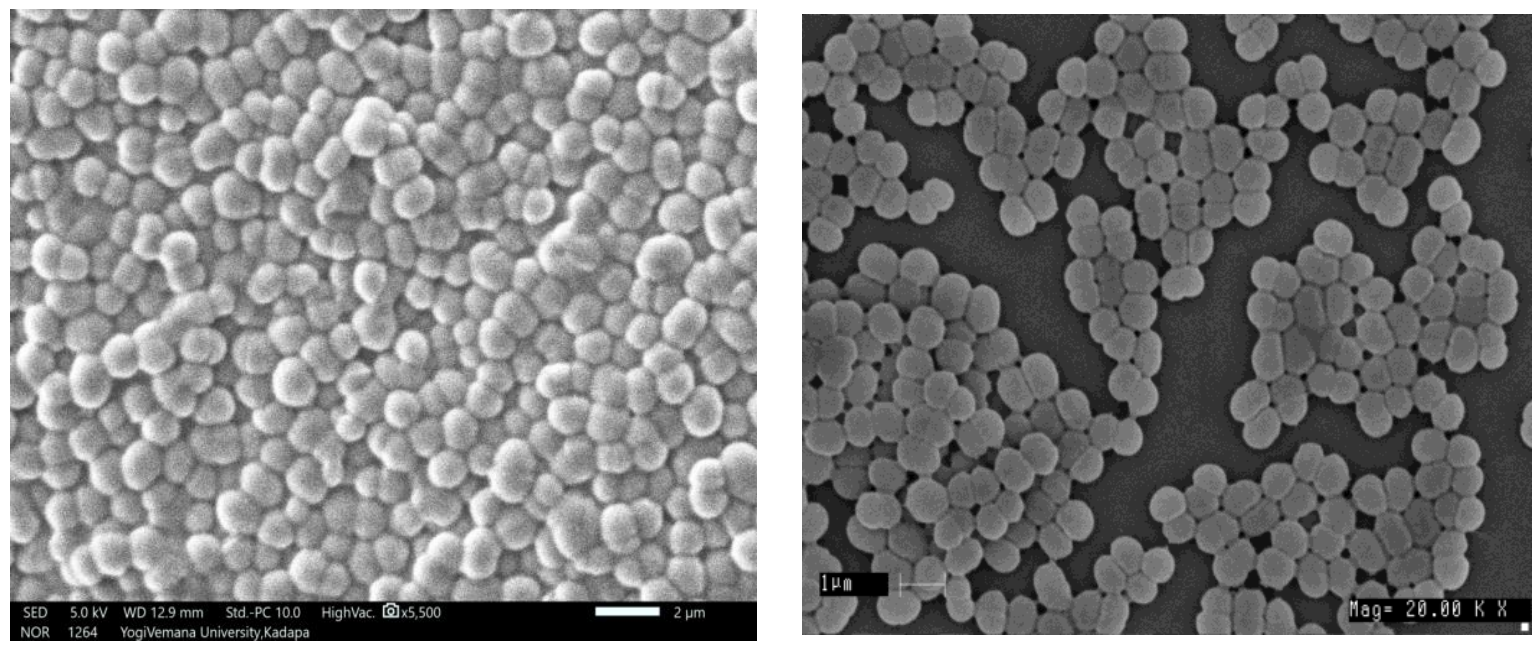

Figure 1. Scanning electron microscopic images of Pediococcus sp. HLV1 at 20 KX magnification. 
Table 1. Morphological, physiological, biochemical characteristics and sugar fermentation of isolated lactic acid bacteria.

\begin{tabular}{|c|c|c|c|c|c|c|}
\hline Tests & Isolate 1 & Isolate 2 & Isolate 3 & Isolate 4 & Isolate 5 & Isolate 6 \\
\hline Cell morphology & Cocci & Cocci & Cocci & Cocci & Cocci & Cocci \\
\hline Gram test & + & + & + & + & + & + \\
\hline Motility & - & - & - & - & - & - \\
\hline Catalase & - & - & - & - & - & - \\
\hline \multicolumn{7}{|c|}{ Biochemical characteristics } \\
\hline Gelatin & - & - & - & - & - & - \\
\hline Indole & - & - & - & - & - & - \\
\hline Methyl red & + & + & + & + & - & - \\
\hline Vogues-Proskauer & - & - & - & - & - & - \\
\hline Citrate & - & - & - & - & - & - \\
\hline $\mathrm{H}_{2} \mathrm{~S}$ production & - & - & - & - & - & - \\
\hline Glycerol & - & - & - & - & - & - \\
\hline \multicolumn{7}{|c|}{ Fermentation of carbohydrates } \\
\hline Glucose & + & + & + & + & + & + \\
\hline Sucrose & + & + & + & + & + & + \\
\hline Fructose & + & + & + & + & + & + \\
\hline Mannose & + & + & + & + & + & + \\
\hline Xylose & + & + & + & + & + & + \\
\hline Arabinose & - & - & - & - & - & - \\
\hline Maltose & - & - & - & - & - & - \\
\hline Galactose & + & + & + & + & + & + \\
\hline Sorbitol & - & - & - & - & - & - \\
\hline $\mathrm{CMC}$ & - & - & - & - & - & - \\
\hline
\end{tabular}

Biochemical properties and sugar utilization tests of the isolates were conducted, and respective results are shown in Table 1. Based on biochemical and sugar utilization, six isolates were primarily identified as the Pediococcus group. As regards the sugar fermentation, all six isolated strains shown are able to ferment glucose, sucrose, galactose, mannose, xylose, fructose, and maltose but not able to ferment arabinose, glycerol, sorbitol, and CMC (carboxymethylcellulose). Color change after $48 \mathrm{~h}$ of incubation confirmed acid production of LAB isolates. Fermenting ability of maltose sugar is the specific quality of the Pediococcus genus [23]. The strain (isolate 1) that showed the highest growth and production at higher temperatures and antimicrobial activity was further selected for molecular identification.

\subsection{Molecular Identification}

The selected culture was subjected to $16 \mathrm{~S}$ rRNA gene sequencing analysis. The DNA of the isolated strain was subjected to PCR amplification of the $16 \mathrm{~S} \mathrm{rRNA}$ gene, and a $649 \mathrm{bp}$ nucleotide sequence was obtained. The obtained sequences were analyzed by comparison with the GenBank database [24]. The isolated culture showed $99 \%$ similarity with strain Pediococcus pentosaceus Ni1142 (accession no. AB598962.1) in BLAST analysis (Figure 2). The isolated culture was named Pediococcus sp. HLV1, and the sequence was submitted to the NCBI databank, and the accession number is MH921241.1.

\subsection{Optimization Studies}

In optimization studies, we tested the isolated LAB to evaluate the type of carbon and nitrogen sources, $\mathrm{pH}$, and temperatures as well as fermentation conditions that affect and support optimal/maximum growth and LA yield. 


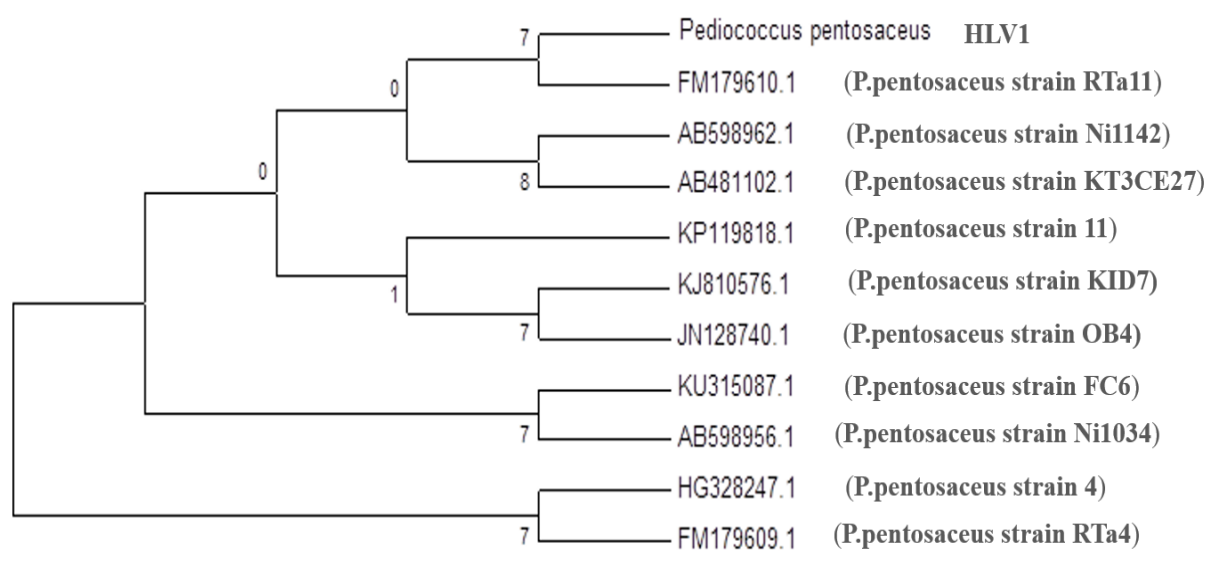

Figure 2. Phylogenetic tree derived from maximum likelihood method by MEGA7.

\subsubsection{Carbon Source}

The type of carbon source is very crucial in the LA fermentation process. This affects the yield and rate of fermentation and the total economics of the process because it shares $50-60 \%$ in fermentation medium cost. Here we tested different carbon sources for lactic acid production. As shown in Figure 3A, the highest LA production was obtained with glucose $(5.06 \%)$, followed by lactose $(4.74 \%)$, fructose $(4.61 \%)$, and sucrose $(4.10 \%)$. The isolated culture was able to utilize xylose to produce LA and obtained comparable concentrations of lactic acid, $3.45 \%$. The lowest lactic acid production was observed in the medium with soy flour, $2.21 \%$. In the case of glucose, the LA yield was approximately $65 \%$ based on the amount of glucose consumed. From this, it can be concluded that glucose and lactose were the preferable sugars for the maximum yield (5.06\% and $4.74 \%$ ) of LA by the isolated Pediococcus sp. HLV1.

\subsubsection{Nitrogen Source}

Lactic acid bacteria require assimilable nitrogen and vitamin supplementation for good growth and lactic acid production, and the cost of such nitrogen sources (yeast extract and peptone) is very high [25]. In this study, experiments were carried out with different nitrogen sources (peptone, yeast extract, beef extract, yeast extract + beef extract, yeast extract + peptone, and beef extract + peptone) to get the knowledge on required nitrogen source for growth and LA production. As shown in Figure 3B, the highest LA production was obtained in medium with $0.3 \%$ peptone $(5.11 \%)$, followed by yeast extract $(4.62 \%)$ and beef extract $(4.50 \%)$. The combination experiments of nitrogen sources produced less lactic acid than the single-nitrogen sources. In previous studies, Nancib et al. [10,26] found that yeast extract is the best supplement in their investigations and suggested that this could be due to the presence of B complex vitamins [27]. On the contrary, the isolated Pediococcus sp. HLV1 preferably utilizes peptone when compared with yeast extract.

\subsection{3. $\mathrm{pH}$}

The initial $\mathrm{pH}$ of the medium is one of the important factors in the screening and selection process of LAB. It is a very critical parameter, and optimum $\mathrm{pH}$ is very essential for better cell growth and LA yield [28]. To investigate the optimum $\mathrm{pH}$ for growth and lactic acid production for the isolated culture fermentation, the $\mathrm{pH}$ of the media was adjusted to different $\mathrm{pH}^{\prime} \mathrm{s}(5.0,6.0,7.0,8.0$, and 9.0). The maximum lactic acid production $(4.3 \%)$ was obtained for the medium with an initial $\mathrm{pH}$ of 7.0 (Figure $3 \mathrm{C}$ ). The final $\mathrm{pH}$ of the medium was decreased to 3.8 from the initial $\mathrm{pH}$ of 7.0. From these results, Pediococcus sp. HLV1 seemed to be a useful LA producer due to its optimum $\mathrm{pH}$ at 7.0 as other LAB, but it has the ability to grow and produce comparable amounts of lactic acid at an acidic $\mathrm{pH}$ of 5.0. This ability of the isolated strain Pediococcus sp. HLV1 is beneficial to avoid the risk of both contamination and neutralization [29-31]. 


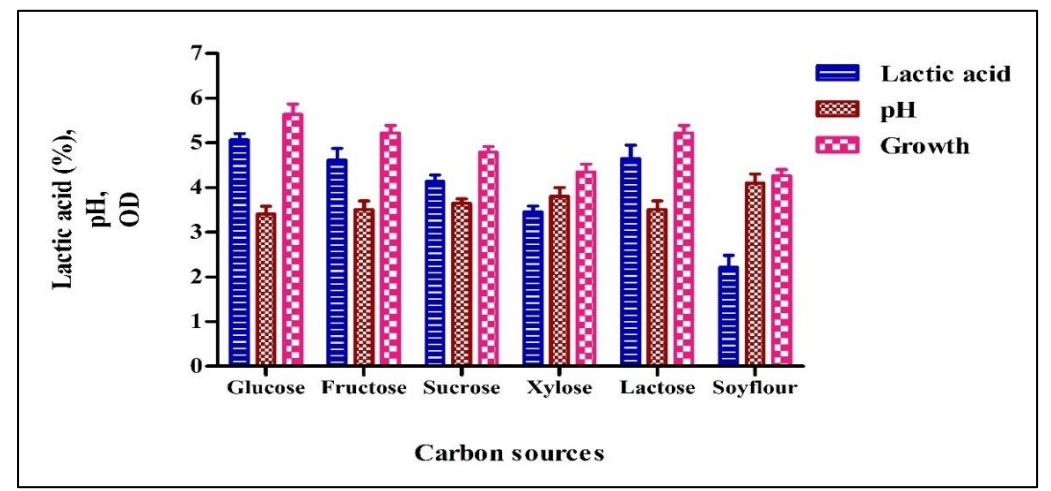

(A)

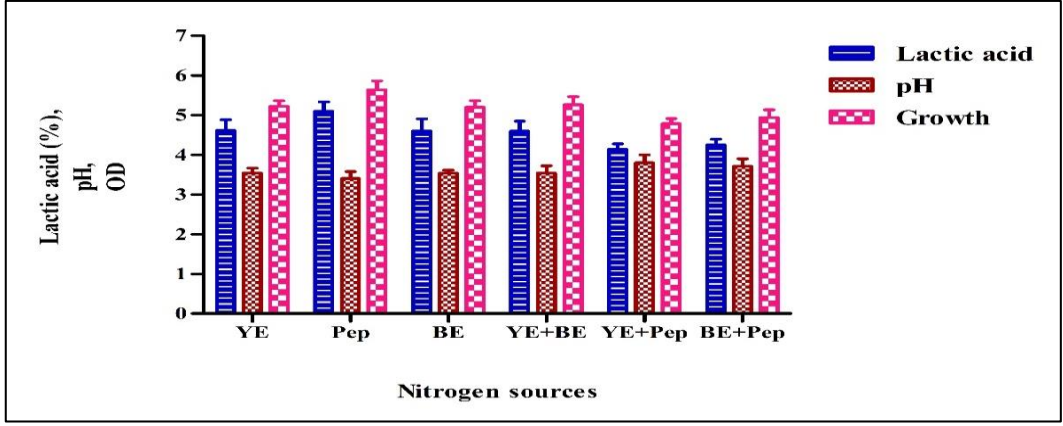

(B)

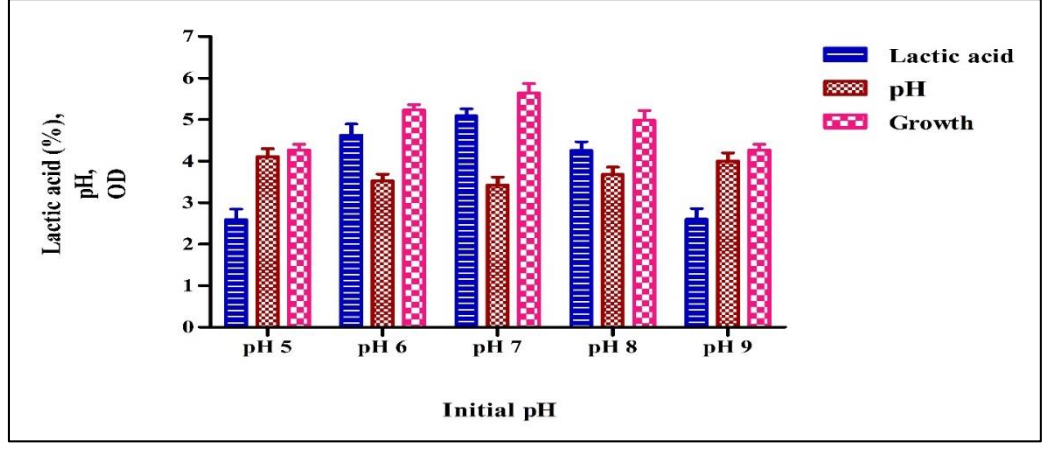

(C)

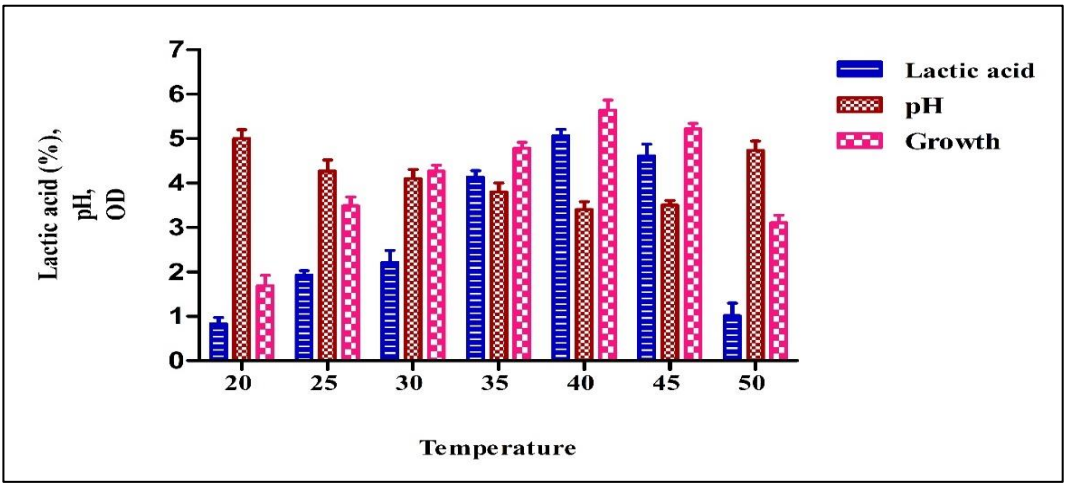

(D)

Figure 3. Production with different carbon sources by Pediococcus pentosaceus HLV1 (A), production with different nitrogen sources by Pediococcus pentosaceus HLV1 (B), production with different $\mathrm{pH}$ 's by Pediococcus pentosaceus HLV1 (C), and production with different temperatures by Pediococcus pentosaceus HLV1 (D).

\subsubsection{Temperature}

In lactic acid fermentation, operating temperature is very crucial because it affects not only the growth of microorganisms but also the yield of the product. It is very essential to 
know the favorable temperature because the different LAB strain has its optimal temperature. To find the optimum temperature for better cell growth and lactic acid production by Pediococcus sp. HLV1, fermentation was carried out at temperatures of 18, 25, 30, 37, and $40{ }^{\circ} \mathrm{C}$. The lactic acid production was increased gradually from 20 to $40{ }^{\circ} \mathrm{C}$ (Figure 3D). The highest production was found at $40^{\circ} \mathrm{C}(5.23 \%)$. Isolated culture showed the best growth at $40^{\circ} \mathrm{C}$. Interestingly, a slight decrease in the amount of lactic acid and growth was observed at $45{ }^{\circ} \mathrm{C}$. Growth and lactic acid production were sharply decreased and recorded the lowest lactic acid yield at $50{ }^{\circ} \mathrm{C}(1.20 \%)$. These results were comparable with those of Alam et al. [32]. However, the isolated strain survived up to $50^{\circ} \mathrm{C}$, and no acid production was detected (data not presented).

\subsection{Antibacterial Activity}

P. pentosaceus is a well-known probiotic organism and shows antipathogen activity towards several harmful bacteria, which is one of the important prerequired characteristics of probiotic organisms. For example, the antimicrobial activity of P. pentosaceus was reported against E. coli [33], L. monocytogenes [34], Staphylococcus aureus and Pseudomonas aeruginosa [35], and Salmonella typhimurium [36]. The isolated culture was preliminarily tested for is antibacterial activity against Gram-positive (Bacillus) and Gram-negative (E. coli) bacteria. It exhibited good performance against both tested bacteria, E. coli (14 mm) and Bacillus (21 mm) (Figure 4A,B). From Figure 4, it is very clear that the inhibition was dose dependent, and the maximum inhibition was shown at $50 \mu \mathrm{L}$ of cell-free suspension. The culture showed a higher inhibition zone for Gram-positive bacteria, B. subtilis, than the Gram-negative bacteria, E. coli. Generally, many antimicrobials work better towards thin peptidoglycan consisting of Gram-negative bacteria than thick peptidoglycan consisting of Gram-positive bacteria. Very few compounds specifically work on Gram-positive bacteria [17]. Apart from medicines, bacteriocin-like inhibitory substances, such as P. pentosaceus-specific exopolysaccharides, were also identified as special function metabolites in P. pentosaceus. Yu et al. [37] determined the production of 3-phenyl acetic acid with broad-spectrum antibacterial (against food-borne pathogens) properties with $P$. pentosaceus SK25, which is isolated from Chinese traditional fermented food.

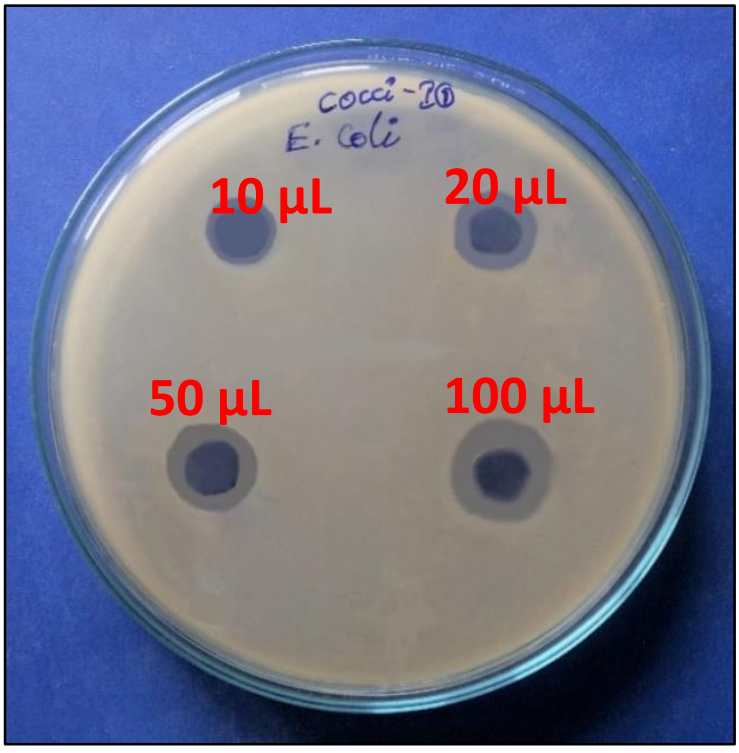

(A)

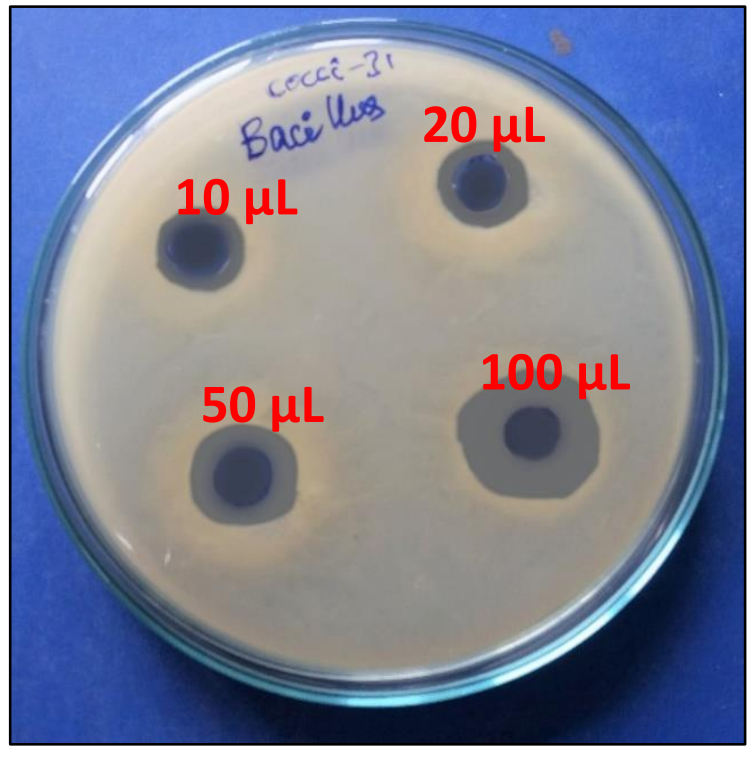

(B)

Figure 4. Antibacterial activity of culture-free supernatant E. coli and Bacillus subtilis (A,B) of Pediococcus pentosaceus HLV1. 


\subsection{Lactic Acid Production from Mango Industrial Waste}

Lactic acid production from fresh mango peel was carried out with a newly isolated LAB strain. The fresh mango peel contained $25 \%$ total solids and $7.2 \%$ reducing sugars. Pectinase enzyme treatment significantly increased the yield of the extract from mango peel, and 550 and $850 \mathrm{~mL}$ of extract were obtained from untreated and enzyme-treated $1 \mathrm{~kg}$ mango peel, respectively. At the end of fermentation, $5.2 \%(v / v)$ LA was produced in the mango peel extract medium supplemented with $0.2 \%$ peptone and $3.2 \%$ in the un-supplemented medium (Figure 5A). This shows that the isolated strain requires an additional nitrogen source for the effective utilization and production of LA from mango peel. The nutrient supplementation would provide required nutrients to overcome nutrient deficiencies and support to produce more fermentation metabolites by keeping the microorganism in the log phase for longer periods. The clear idea on the influence of nutrient supplementation required more experiments with different nutrients at different amounts and using different feeding methods. In a nutrient unsupplemented medium, the fermentation and utilization of carbohydrates are slow because of insufficient growth nutrients in the peel medium. Jawad et al. [14] investigated the production of LA from mango peel and reported a very low yield, $17.4 \mathrm{~g} / \mathrm{L}$, through spontaneous anaerobic fermentation with the indigenous microbial consortium and with direct fermentation of blended mango peel. Changes in $\mathrm{pH}$ and growth of microorganisms were depicted in Figure 5B. Decrease in $\mathrm{pH}$ was rapid in the case of supplemented medium (3.2), and the $\mathrm{pH}$ was recorded to be 5.2 in the case of control medium. Similarly, the growth of the culture was increased rapidly and reached to $0.8 \mathrm{OD}$ in peptone-supplemented medium. The data clearly support how high LA was produced in peptone-added medium when compared with control. In addition to the optimization of the fermentation factors $\mathrm{pH}$, temperature, and fermentation time, the medium composition is one factor that plays a crucial role in the production of LA [38].

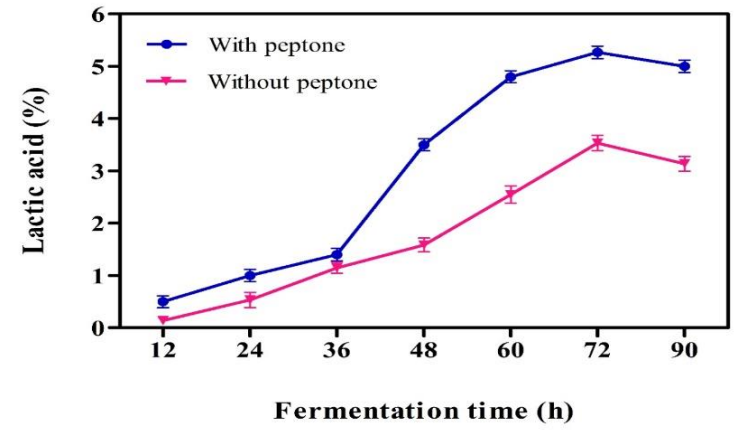

(A)

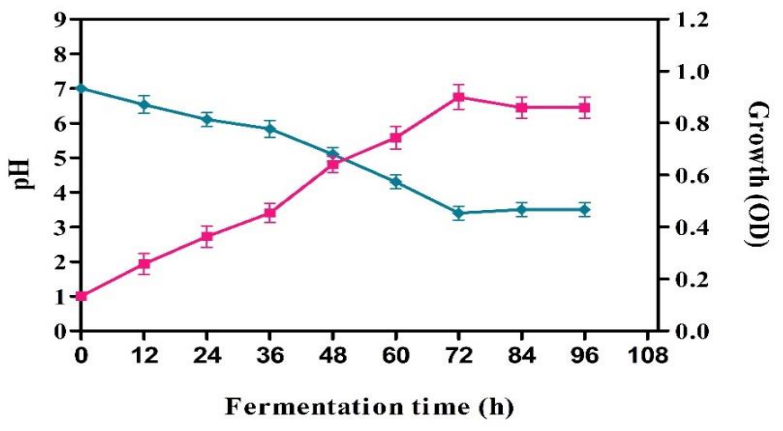

$\rightarrow \mathrm{pH}$

- Growth

(B)

Figure 5. (A) Lactic acid production from mango peel by Pediococcus sp. HLV1; (B) pH and growth kinetics in lactic acid production from mango peel (peptone added) by Pediococcus sp. HLV1. 


\section{Conclusions}

Lactic-acid-producing bacteria were successfully isolated from fermented idly batter, and based on 16S rRNA gene sequencing, the isolate showed 99\% homology with Pediococcus pentosaceus Ni1142 and was named Pediococcus sp. HLV1. The isolated strain showed better growth and LA production with $10 \%$ glucose as carbon source and $0.3 \%$ peptone as nitrogen source under initial medium at $\mathrm{pH} 7.0$ and $40{ }^{\circ} \mathrm{C}$, resulting in a production of $5.5 \%$ $(w / v)$ LA. The isolated strain was effectively inhibited by both Gram-positive and Gramnegative bacteria in a preliminary evaluation. Mango peel extract was effectively utilized and produced $5.2 \%(w / v)$ of LA by the supplementation of peptone. Peptone supplementation enhanced cell growth and subsequently helped in higher LA production. In conclusion, the isolated LAB, Pediococcus sp. HLV1, thermophilic in nature, was able to grow and produce LA at a high temperature $\left(45^{\circ} \mathrm{C}\right)$ and had survivability at $50{ }^{\circ} \mathrm{C}$. The present study also revealed that the isolated strain is able to utilize mango peel as agro-industrial biomass and could be useful for lactic acid production using various renewable substrates.

Author Contributions: H.K. conducted the literature survey and investigation; V.R.L. and S.V.C. were involved in the conceptualization, experiment design, and MS preparation; Y.-J.W., K.S.A., Y.B.E. and R.G. reviewed and edited the MS. All authors have read and agreed to the published version of the manuscript.

Funding: The authors acknowledge the financial support for project number RSP-2021/189, King Saud University, Riyadh, Saudi Arabia.

Institutional Review Board Statement: Not applicable.

Informed Consent Statement: Not applicable.

Data Availability Statement: Not applicable.

Conflicts of Interest: The authors declare no conflict of interest.

\section{References}

1. Available online: http://www.grandviewresearch.com/industryanalysis/lactic-acid-and-poly-lactic-acid-market (accessed on 10 December 2021).

2. Ghaffar, T.; Irshad, M.; Anwar, Z.; Aqil, T.; Zulifqar, Z.; Tariq, A.; Kamran, M.; Ehsan, N.; Mehmood, S. Recent trends in lactic acid biotechnology: A brief review on production to purification. J. Radiat. Res. Appl. Sci. 2014, 7, 222-229. [CrossRef]

3. Fevria, R.; Hartanto, I. Isolation and characterization of lactic acid bacteria (Lactobacillus sp.) from strawberry (Fragaria vesca). Int. J. Phys Conf. Ser. 2009, 1371, 012086. [CrossRef]

4. Cui, F.; Li, Y.; Wan, C. Lactic acid production from corn stover using mixed cultures of Lactobacillus rhamnosus and Lacto-bacillus brevis. Biores. Technol. 2011, 102, 1831-1836. [CrossRef] [PubMed]

5. Nancib, A.; Nancib, N.; Boudrant, J. Production of lactic acid from date juice extract with free cells of single and mixed cultures of Lactobacillus casei and Lactococcus lactis. World J. Microbiol. Biotechnol. 2009, 25, 1423-1429. [CrossRef]

6. Agaliya, P.J.; Jeevaratnam, K. Molecular characterization of lactobacilli isolated from fermented idli batter. Braz. J. Microbiol. 2013, 44, 1199-1206. [CrossRef] [PubMed]

7. Sathe, G.B.; Mandal, S. Fermented products of India and its implication: A review. Asian J. Dairy Food Res. 2016, 35, 1-9. [CrossRef]

8. Abdel-Rahman, M.A.; Tashiro, Y.; Sonomoto, K. Recent advances in lactic acid production by microbial fermentation processes. Biotechnol. Adv. 2013, 31, 877-902. [CrossRef]

9. Sakdaronnarong, C.; Srimarut, N.; Lucknakhul, N.; Na-songkla, N.; Jonglertjunya, W. Two-step acid and alkaline methanolysis/alkaline peroxide fractionation of sugarcane bagasse and rice straw for production of polylactic acid precursor. Bio-Chem. Eng. J. 2014, 85, 49-62.

10. Nancib, N.; Nancib, A.; Boudjelal, A.; Benslimane, C.; Blanchard, F.; Boudrant, J. The effect of supplementation by different nitrogen sources on the production of lactic acid from date juice by Lactobacillus casei subsp. rhamnosus. Bioresour. Technol. 2001, 78, 149-153. [CrossRef]

11. Neu, A.-K.; Pleissner, D.; Mehlmann, K.; Schneider, R.; Puerta-Quintero, G.I.; Venus, J. Fermentative utilization of coffee mucilage using Bacillus coagulans and investigation of down-stream processing of fermentation broth for optically pure $1(+)$-lactic acid production. Bioresour. Technol. 2016, 211, 398-405. [CrossRef]

12. Reddy, L.V.; Reddy, O.V.S.; Wee, Y.J. Production of ethanol from mango (Mangifera indica L.) peel by Saccharomyces cerevisiae CFTRI101. Afr. J. Biotechnol. 2011, 10, 4183-4189.

13. Avula, S.V.; Reddy, S.; Reddy, L.V. The Feasibility of Mango (Mangifera indica L.) Peel as an Alternative Substrate for Butanol Production. BioResources 2015, 10, 4453-4459. [CrossRef] 
14. Jawad, A.H.; Alkarkhi, A.F.; Jason, O.C.; Easa, A.M.; Norulaini, N.N. Production of the lactic acid from mango peel wasteFactorial experiment. J. King Saud Univ. Sci. 2013, 25, 39-45. [CrossRef]

15. Sreedhara, M.M.; Vijaya, S.R.O. Lactic Acid Production Using Mango Peel: Studies on Lactic Acid Production Using Mango Peel and Its Use in Bio-Film Preparation; LAP Lambert Academic Publishing: Sunnyvale, CA, USA, 2019.

16. Reddy, L.V.; Sreeveda, A.; Park, I.H.; Wee, Y.J. Isolation and characterization of Clostridia from the feces of wild rabbit and swine for hemicellulosic acetone-butanol-ethanol (ABE) production. BioResources 2019, 14, 5832-5844.

17. Srihasam, S.; Thyagarajan, K.; Korivi, M.; Lebaka, V.R.; Mallem, S.P.R. Phytogenic Generation of NiO Nanoparticles Using Stevia Leaf Extract and Evaluation of Their In-Vitro Antioxidant and Antimicrobial Properties. Biomolecules 2020, 10, 89. [CrossRef]

18. Miller, G.L. Use of Dinitrosalicylic Acid Reagent for Determination of Reducing Sugar. Anal. Chem. 1954, 31, 426-428. [CrossRef]

19. Pal, V.; Jamuna, M.; Jeevaratnam, K. Isolation and characterization of bacteriocin producing lactic acid bacteria from a south Indian special dosa (Appam) batter. J. Cult. Collect. 2005, 4, 53-60.

20. Ruiz Rodriguez, L.G.; Mohamed, F.; Bleckwedel, J.; Medina, R.; De Vuyst, L.; Hebert, E.M.; Mozzi, F. Diversity and functional properties of lactic acid bacteria isolated from wild fruits and flowers present in Northern Argentina. Front. Microbiol. 2019, 10, 1091. [CrossRef]

21. Patil, M.M.; Pal, A.; Anand, T.; Ramana, K.V. Isolation and characterization of lactic acid bacteria from curd and cucumber. Indian J. Biotechnol. 2010, 9, 166-172.

22. Olasupo, N.A.; Schillinger, U.; Holzapfel, W.H. Studies on some technological properties of predominant lactic acid bacteria isolated from nigerian fermented foods. Food Biotechnol. 2001, 15, 157-167. [CrossRef]

23. Garvie, E.I. Genus Pediococcus. In Bergey's Manual of Systematic Bacteriology; Sneath, P.H.A., Mair, N.S., Sharpe, M.E., Holt, J.G., Eds.; The Williams \& Wilkins Co.: Baltimore, MD, USA, 1986; Volume 2, pp. 1075-1079.

24. NCBI Resources Genbank. Available online: http://www.ncbi.nlm.nih.gov/genbank/ (accessed on 19 September 2012).

25. Leh, M.B.; Charles, M. Lactic acid production by batch fermentation of whey permeate: A mathematical model. J. Ind. Microbiol. Biotechnol. 1989, 4, 65-70. [CrossRef]

26. Nancib, N.; Nancib, A.; Boudjelal, A.; Benslimane, C.; Blanchard, F.; Boudrant, J. Joint effect of nitrogen sources and B vitamin supplementation of date juice on lactic acid production by Lactobacillus casei subsp. rhamnosus. Bioresour. Technol. 2005, 96, 63-67. [CrossRef] [PubMed]

27. Cheng, P.; Muller, S.; Bajpai, R.; Lannotti, E.L. Lactic acid production from enzyme thinned corn starch using Lactobacillus amylovorus. J. Ind. Microbiol. 1991, 7, 27-34. [CrossRef]

28. Abdel-Rahman, M.A.; Sonomoto, K. Opportunities to overcome the current limitations and challenges for efficient microbial production of optically pure lactic acid. J. Biotechnol. 2016, 236, 176-192. [CrossRef] [PubMed]

29. Åkerberg, C.; Hofvendahl, K.; Zacchi, G.; Hahn-Hägerdal, B. Modelling the influence of pH, temperature, glucose and lactic acid concentrations on the kinetics of lactic acid production by Lactococcus lactis ssp. lactis ATCC 19435 in whole-wheat flour. Appl. Microbiol. Biotechnol. 1998, 49, 682-690. [CrossRef]

30. Calabia, B.P.; Tokiwa, Y.; Aiba, S. Fermentative production of 1-(+)-lactic acid by an alkaliphilic marine microorganism. Biotechnol. Lett. 2011, 33, 1429-1433. [CrossRef]

31. Ding, S.; Tan, T. 1-lactic acid production by Lactobacillus casei fermentation using different fed-batch feeding strategies. Process Biochem. 2006, 41, 1451-1454. [CrossRef]

32. Alam, M.T.; Mahato, A.K.; Kumari, L.; Singh, R.S. Fermentative study on optimization of lactic acid production from cane sugar by Lactobacillus spp. Eur. J. Molec. Clin. Med. 2021, 8, 712-723.

33. Nze, U.C.; Beeman, M.G.; Lambert, C.J.; Salih, G.; Gale, B.K.; Sant, H.J. Hydrodynamic cavitation for the rapid separation and electrochemical detection of Cryptosporidium parvum and Escherichia coli O157:H7 in ground beef. Biosens. Bioelectron. 2019, 135, 137-144. [CrossRef]

34. Orsi, R.H.; Wiedmann, M. Characteristics and distribution of Listeria spp., including Listeria species newly described since 2009 Appl. Microbiol. Biotechnol. 2016, 100, 5273-5287. [CrossRef]

35. Lele, V.; Zelvyte, R.; Monkeviciene, I.; Kantautaite, J.; Stankevicius, R.; Ruzauskas, M.; Sederevicius, A.; Antanaitis, R.; Bartkiene, E. Milk production and ruminal parameters of dairy cows fed diets containing Lactobacillus sakei KTU05-6 and Pediococcus pentosaceus BaltBio02. Pol. J. Vet. Sci. 2019, 22, 327-335. [PubMed]

36. Nanasombat, S.; Treebavonkusol, P.; Kittisrisopit, S.; Jaichalad, T.; Phunpruch, S.; Kootmas, A.; Nualsri, I. Lactic acid bacteria isolated from raw and fermented pork products: Identification and characterization of catalase-producing Pediococcus pentosaceus. Food Sci. Biotechnol. 2017, 26, 173-179. [CrossRef] [PubMed]

37. Yu, S.; Zhou, C.; Zhang, T.; Jiang, B.; Mu, W. Short communication: 3-phenyllactic acid production in milk by Pediococcus pentosaceus SK25 during laboratory fermentation process. J. Dairy Sci. 2015, 98, 813-817. [CrossRef]

38. Reddy, L.V.; Kim, Y.-M.; Yun, J.-S.; Ryu, H.-W.; Wee, Y.-J. 1-Lactic acid production by combined utilization of agricultural bioresources as renewable and economical substrates through batch and repeated-batch fermentation of Enterococcus faecalis RKY1. Bioresour. Technol. 2016, 209, 187-194. [CrossRef] 